\title{
A TaqMan-based real-time PCR assay for specific detection of novel duck reovirus in China
}

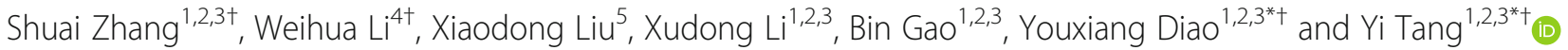

\begin{abstract}
Background: In China, Newly emerging duck reovirus (NDRV) variants have been causing major disease problems in cherry valley ducks. NDRV has the potential to cause high morbidity and 5-50\% mortality rates. Severe hemorrhagic-necrosis in the liver and spleen were commonly seen in NDRV affected ducks. The availability of upgraded methods for rapid diagnosis of newly emerging DRV variants is crucial for successful DRV infection control and prevention.

Results: In this study, we present a TaqMan-based real-time PCR assay (RT-qPCR) for the detection of NDRV infection. Using the conserved regions within the NDRV genome, we designed the specific primers and probe. The lower limit of detection for NDRV infection was 10 copies/ $\mu \mathrm{L}$ (Ct values: 38.3 ) after the optimization of the RT-qPCR conditions. By cross-checking with other duck viral pathogens, no crossreactivity was observed confirming the assay was highly specific for the detection of NDRV. Reproducibility of the RT-qPCR was confirmed by intra- and inter-assay variability was less than $2.91 \%$ (Intra-assay variability of Ct values: $0.07-1.48 \%$; Interassay variability of Ct values: $0.49-2.91 \%)$. This RT-qPCR and conventional PCR (CPCR) detected one hundred and twenty samples of NDRV infection from different regions. The result shows that the positive rates were 94.17 and $84.17 \%$ respectively. The detection rate of RT-qPCR rapid detection assay was 10\% higher than that of the CPCR method.
\end{abstract}

Conclusion: This research developed a highly sensitive, specific, reproducible and versatile of RT-qPCR for quantitatively detecting NDRV. It can be used to study the pathogenesis and epidemiology investigation of NDRV.

Keywords: Novel duck reovirus, oC gene, Real-time PCR assay, TaqMan-based probe, Detection method

\footnotetext{
* Correspondence: yxdiao@126.com; tyck288@163.com

†Shuai Zhang, Weihua Li, Youxiang Diao and Yi Tang contributed equally to this work.

${ }^{1}$ College of Animal Science and Technology, Shandong Agricultural University, 61 Daizong Street, Tai'an 271018, Shandong Province, China

Full list of author information is available at the end of the article
}

C C The Author(s). 2020 Open Access This article is licensed under a Creative Commons Attribution 4.0 International License, which permits use, sharing, adaptation, distribution and reproduction in any medium or format, as long as you give appropriate credit to the original author(s) and the source, provide a link to the Creative Commons licence, and indicate if changes were made. The images or other third party material in this article are included in the article's Creative Commons licence, unless indicated otherwise in a credit line to the material. If material is not included in the article's Creative Commons licence and your intended use is not permitted by statutory regulation or exceeds the permitted use, you will need to obtain permission directly from the copyright holder. To view a copy of this licence, visit http://creativecommons.org/licenses/by/4.0/ The Creative Commons Public Domain Dedication waiver (http://creativecommons.org/publicdomain/zero/1.0/) applies to the data made available in this article, unless otherwise stated in a credit line to the data. 


\section{Background}

Duck reovirus (DRV), a fatal aquatic bird pathogen, is a member of the genus Orthoreovirus in the family Reoviridae [1]. Muscovy Duck Reovirus (MDRV) was first identified in South Africa [2], and then was isolated in France [3], Israel [1], Italy [4] and Germany [5]. In China, DRV was firstly noted in 1997 [6]. It showed a series of clinical symptoms, including general weakness, diarrhea, growth retardation, pericarditis, swollen liver and spleen covered with small white necrotic foci [7-9]. Based on electrophoretic mobility, the DRV contains 10 double-stranded RNA (dsRNA) genome segments which can be separated in to three size classes, including large (L1-L3), medium (M1-M3) and small (S1-S4) [10-14].

In recent years, a new duck reovirus disease was detected in China. The disease could affect different breeds of ducks and goslings. The main characteristic of the disease is hemorrhagic-necrosis in the liver and spleen $[10,12,13,15,16]$. The novel duck reovirus is distinct from previous MDRV isolates [9]. Thus, to distinguish it from the "classical" MDRV, the reovirus has been categorized as "novel" duck reovirus (NDRV) $[15,17]$. Recently, Related research found that a new variant of a duck orthoreovirus that is significantly different from any previously reported waterfowl-derived othoreovirus, causing duck spleen necrosis [18]. The complete sequences of the 10 genome segments of NDRV have been completely determined [11]. NDRV $\mathrm{S} 1$ segment is similar to avian reovirus (ARV), but it is distinct from classical MDRV. NDRV S1 contains three sequential overlapping ORFs, encoding p10, p18, and $\sigma \mathrm{C}$, but in MDRV $\mathrm{p} 10$ and $\sigma \mathrm{C}$ proteins are encoded by the S4 segment and p18 is not present [10-13, 16].

Rapid detection methods are the key for successful NDRV infection control. For many years now, quantitative real time PCR has been a standard diagnostic method, due to its rapid nature, sensitivity, reproducibility, and the reduced risk of false positives from the mispriming of the amplification primers. For viral epidemiological surveillance and pathogenesis studies, this method had been widely used [19-22]. Currently there are not any reports on a TaqMan-based realtime PCR assay for the specific detection of the novel reovirus infection. Thus, it is critical to develop the TaqMan-based real-time PCR assay of detecting NDRV infection.

In this study, we isolated novel reovirus distinct from previous duck reoviruses identified in China and developed a TaqMan probe-based RT-qPCR method which was developed for precise detection of NDRV infection based on specific primers and probe. The specific primers and probe were designed by targeting the conserved region of the NDRV S2 gene after bioinformatics analysis. The TaqMan-based real-time PCR assay was utilized extensively for virus pathogenesis studies and epidemiological investigations of NDRV.

\section{Results}

\section{The selection and design of primers and probe}

The probe and primers used in the study were designed based on the S2 gene of NDRV (Table 1). The primers can amplify fragments of $85 \mathrm{bp}$ in length. In Fig. 1, the S2 genome segment alignment of different avian orthoreoviruses were compared by mVISTA method and ClustalW method. The results showed that the primers and probes failed to align with sequences of other poultry reoviruses. Also, primers and probe were verified by the Basic Local Alignment Search Tool (BLAST, https://blast.ncbi.nlm.nih.gov/Blast.cgi) for specificity analysis [18].

\section{Phylogenetic analysis of $\sigma \mathrm{C}$ genes}

From GenBank (www.ncbi.nlm.nih.gov), thirteen ARVs, four MDRVs, and four DRVs strains were downloaded to compare the difference among SDHZYC and other DRV, ARV and MDRV strains. The SDHZYC (GenBank accession number MK789277) strain was a new clone from a field isolate. By constructing the phylogenetic tree of $\sigma \mathrm{C}$ genes (Fig. 2) and homology analysis, we observed that the SDHZYC strains grouped with China

Table 1 Primers and probe for NDRV detection used in this study

\begin{tabular}{|c|c|c|c|c|}
\hline RT-PCR & Oligo & Sequence $\left(5^{\prime}-3^{\prime}\right)$ & Length (bp) & Positions (Segment \\
\hline \multirow[t]{3}{*}{ Realtime } & Forward primer & CCCGGATTCTCGATGAATGGT & 21 & $958-978(S 2)$ \\
\hline & Probe & FAM-AACGCCTGTGCACGAGCTGAAC-3'-TAMRA & 22 & $981-1022(S 2)$ \\
\hline & Reverse primer & CGACCCACTGCTGGATACAAG & 21 & $1022-1042(S 2)$ \\
\hline \multirow[t]{2}{*}{$\sigma C$ full-length } & Forward primer & ATGGATCGCAACGAGGTGATAC & 22 & $571-592(S 1)$ \\
\hline & Reverse primer & CTAGCCCGTGGCGACGGT & 18 & 1519-1536(S1) \\
\hline \multirow[t]{2}{*}{$\sigma C$ conventional } & Forward primer & TGAGACGCCTGACTACGATT & 20 & 707-726(S1) \\
\hline & Reverse primer & ATGCTTGGAGTGAGACGACT & 20 & 1056-1075(S1) \\
\hline
\end{tabular}

${ }^{a}$ FAM, 6-carboxy-fluoresce; TAMRA, 5-Carboxytetramethylrhodamine 


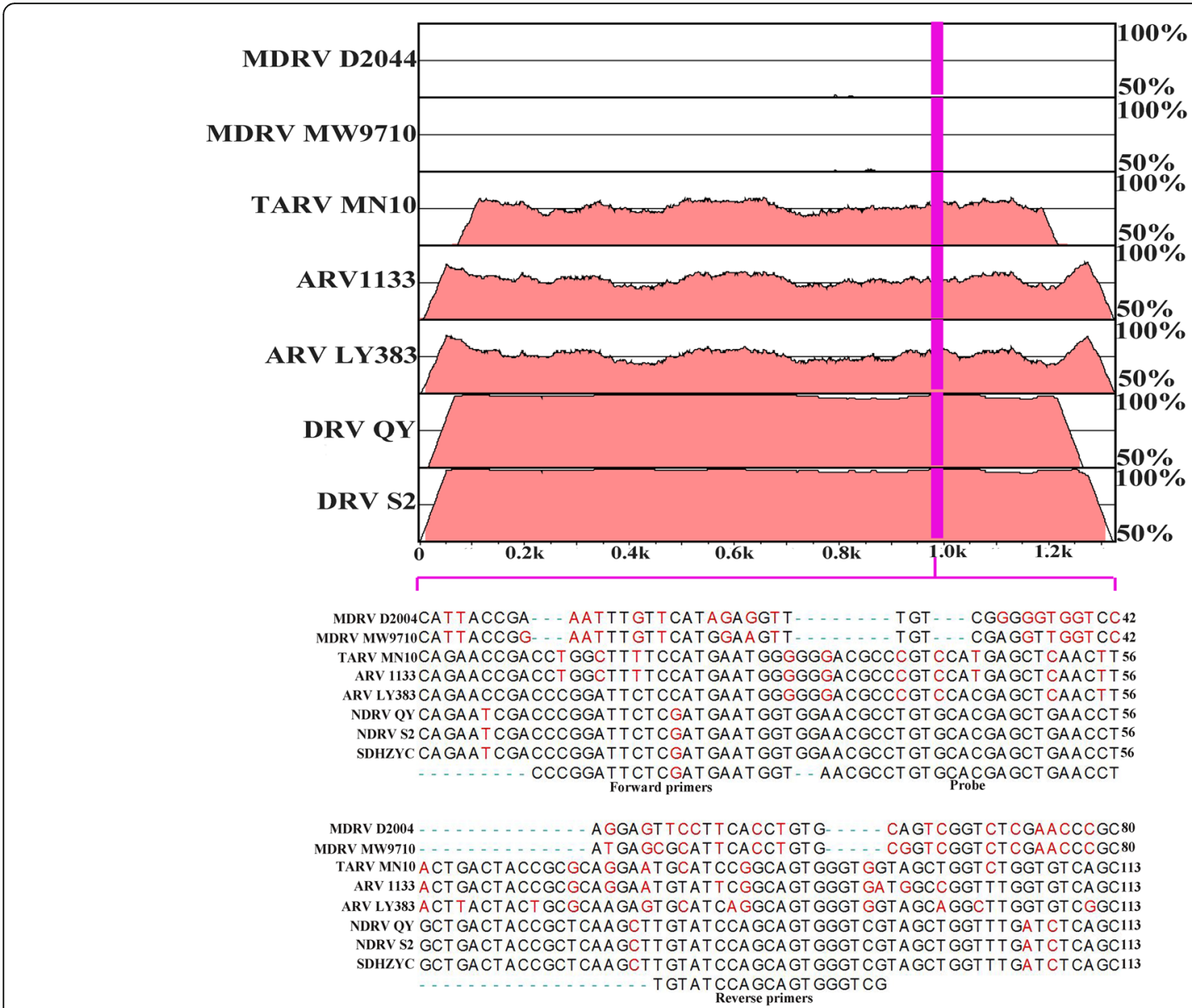

Fig. 1 S2 genome segment alignment of different avian reovirus by mVISTA method (upper figure) and ClustalW method (lower figure); The figures illustrate alignment results of the DRV (HN5d, QY, and S2) in comparisons with ARV (MN10, 1133, and LY383) and MDRV strains (D2044 and MW9710) retrieved from GenBank; Areas in pink color represent $\geq 95 \%$ similarities; and areas in white represent <95\% similarities. The scale bar measures approximate length of the concatenated genome. The lower figure shows the primers and probe were shown according to the alignment result

DRV strains. The SDHZYC strain shared 96.9-97.2\% sequence similarities with strains QY (KF685545), NP03(KC312699), S1(KF154116) and TH11(JX826587). The SDHZYC strain only shared approximately $41.8 \%$ with ARV and 51\% with MDRV. These suggest that the genetic evolutionary relationship of the SDHZYC strain is more similar to China DRV strains, and NDRV is caused by a mutation in DRV [18].

\section{Standard curve, sensitivity and repeatability}

The results are showed in Fig. 3A, the triplicate standard curve plots indicate a linear correlation between the Log of the copy number and the CT. The standard curve was $\mathrm{Y}=-3.3468 \mathrm{X}+41.681$, of which $\mathrm{Y}=$ threshold cycle and $\mathrm{X}=\log$ sta. The linear correlation $\left(\mathrm{R}^{2}\right)$ of the standard curve was 0.9988 . The concentration of plasmid was from $1.0 \times 10^{8}$ to $1.0 \times 10^{2}$ copies $/ \mu \mathrm{L}$. The range of DNA copy numbers of the standard curve was from $1.0 \times 10^{7.9}$ to $1.0 \times 10^{2.2}$ copies $/ \mu \mathrm{L}$.

To evaluate the sensitivity of the RT-qPCR assay, the DNA standards plasmid was diluted from $1.0 \times 10^{9}$ copies $/ \mu \mathrm{L}$ to $1.0 \times 10^{\circ}$ copies $/ \mu \mathrm{L}$. After confirmation, the lowest detection limit of the RT-qPCR was $1.0 \times 10^{1}$ copies/ $\mu \mathrm{L}$ (Ct values: 38.3) (Fig. 3B1). By comparison, the lowest detection standard of conventional PCR only was $1.0 \times 10^{4}$ copies/ $\mu \mathrm{L}$ (Fig. 3B2).

On 3 different days, 10-fold serial dilutions of standard NDRV plasmid DNA (concentration from $1.0 \times 10^{8}$ to $1.0 \times 10^{1}$ copies $/ \mu \mathrm{L}$ ) were used to test the intra- and inter-assay reproducibility. All samples were detected in triplicate [19]. In the detection of the intra-assay, the CVs ranged from 0.07 to $1.48 \%$, and the result of the inter-assay CVs ranged from 0.49 to $2.91 \%$ (Table 2). It shows that the repeatability of RT-qPCR is high. 


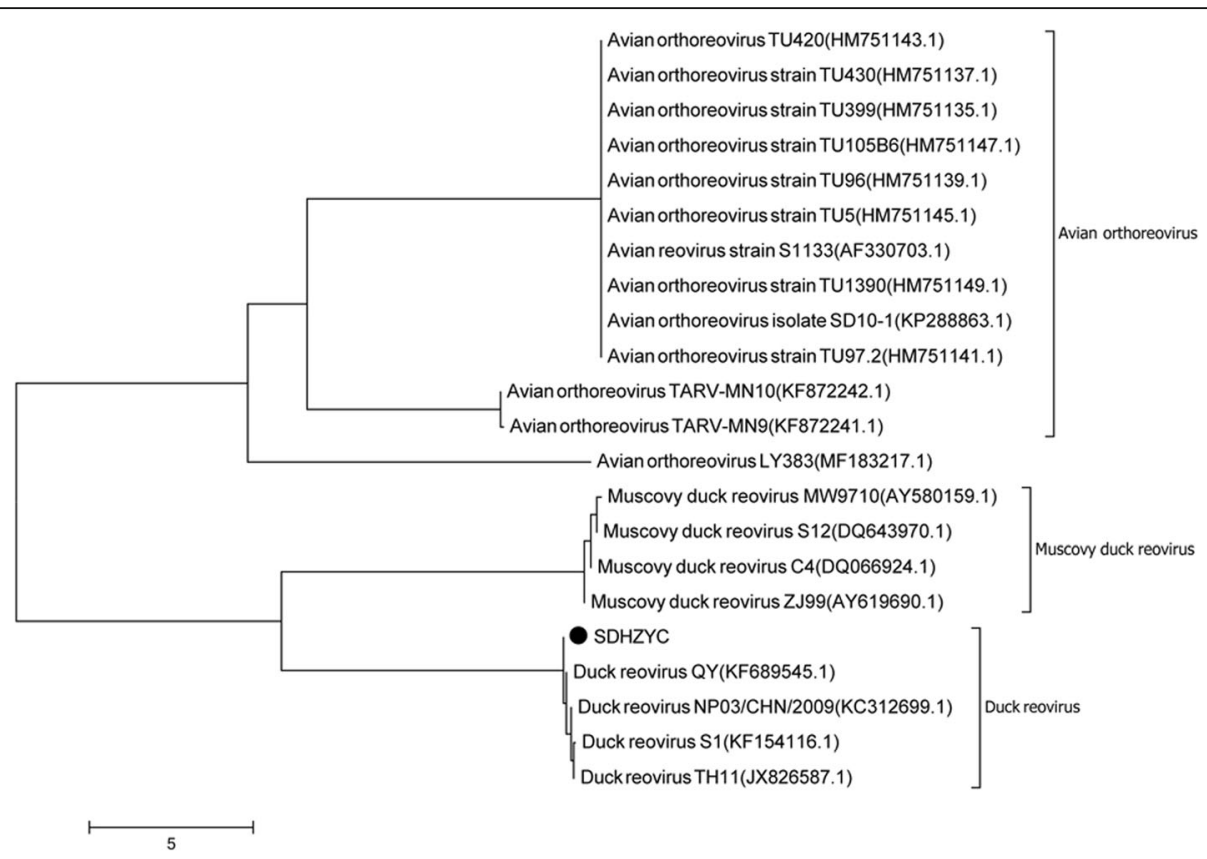

Fig. 2 Phylogenetic relationship between $\operatorname{SDHZYC}(\bullet)$ and other avian reovirus strains based on the $\sigma \mathrm{C}$ gene in the phylogenetic tree. The tree was constructed using the neighbour-joining algorithm of MEGA5.0, and 1000 bootstrap replicates were performed to assign confidences to the groupings. The tree is drawn to scale, with branch lengths in the same units as those of the evolutionary distances used to infer the phylogenetic tree. Note: The SDHZYC strain was marked with filled circles

\section{Specificity analysis of the RT-qPCR reaction}

Eight different avian viruses were used to test the specificity of RT-qPCR detection. After the detection, NDRV develops a strong response signal. But H9N2 AIV, DTMUV, GPV, N-GPV, DHAV-1, DHAV-3, DuCV, DPV, and Nuclease-free water were not amplified (Fig. 4). The results show that the PCR is specific for NDRV when tested against the listed pathogens.

\section{Experimentally infected ducklings}

The major pathological changes of the ducklings include enlarged liver hepatomegaly with bleeding and necrosis, brittle texture, red darken, splenomegaly, patchy hemorrhagic necrosis [23] (Fig. 5). Ducks in groups 2 did not show clinical signs. The most important purpose of using experimentally infected ducklings is to validate the RT-qPCR using clinical samples of RT-qPCR. Therefore, we collected thirtynine samples respectively from different affected organs at $24 \mathrm{~h}, 48 \mathrm{~h}$ and $72 \mathrm{~h}$, including heart, liver, spleen, lung, kidney, pancreas, stomach, brain, intestinal, bursa, thymus, stool and serum. The result was showed in Table 3. After conventional RT-PCR assay and real-time PCR assay, thirty-nine samples of group 2 are negative. Compare to conventional RTPCR assay, real-time PCR assay detected NDRV earlier, and more frequently. This means that real-time
PCR assay had high sensitivity and is appropriate for the detection of NDRV.

\section{Clinical sample detection}

One hundred and twenty clinical spleen samples from the cherry valley ducklings with NDRV were identified by the TaqMan based real-time PCR and conventional PCR assays. Of these, 113 samples were RT-qPCR positive, and only 101 samples were $\mathrm{CPCR}$ positive. The results are presented in Table 4. Statistical analysis showed a difference between the two methods was significant $(P<0.05)$ in the detection of clinical samples. The positive rate of NDRV was $84.17 \%$ according to the detection of conventional PCR. However, the positive rate of NDRV was $94.17 \%$ through the detection of the RT-qPCR assay established in the study. In the same run described above, samples from non-inoculated SPF chicken embryo were tested negative by RT-qPCR and cPCR. The Copy number of clinical samples were shown in Table 5.

\section{Discussion}

In China, NDRV has emerged in recent years and is a current common genotype $[13,16]$. Recently, a group of newly emerging DRVs [24-26] was confirmed and characterized in Cherry Valley duck in China [18]. The NDRV from the mainly infected ducklings caused 


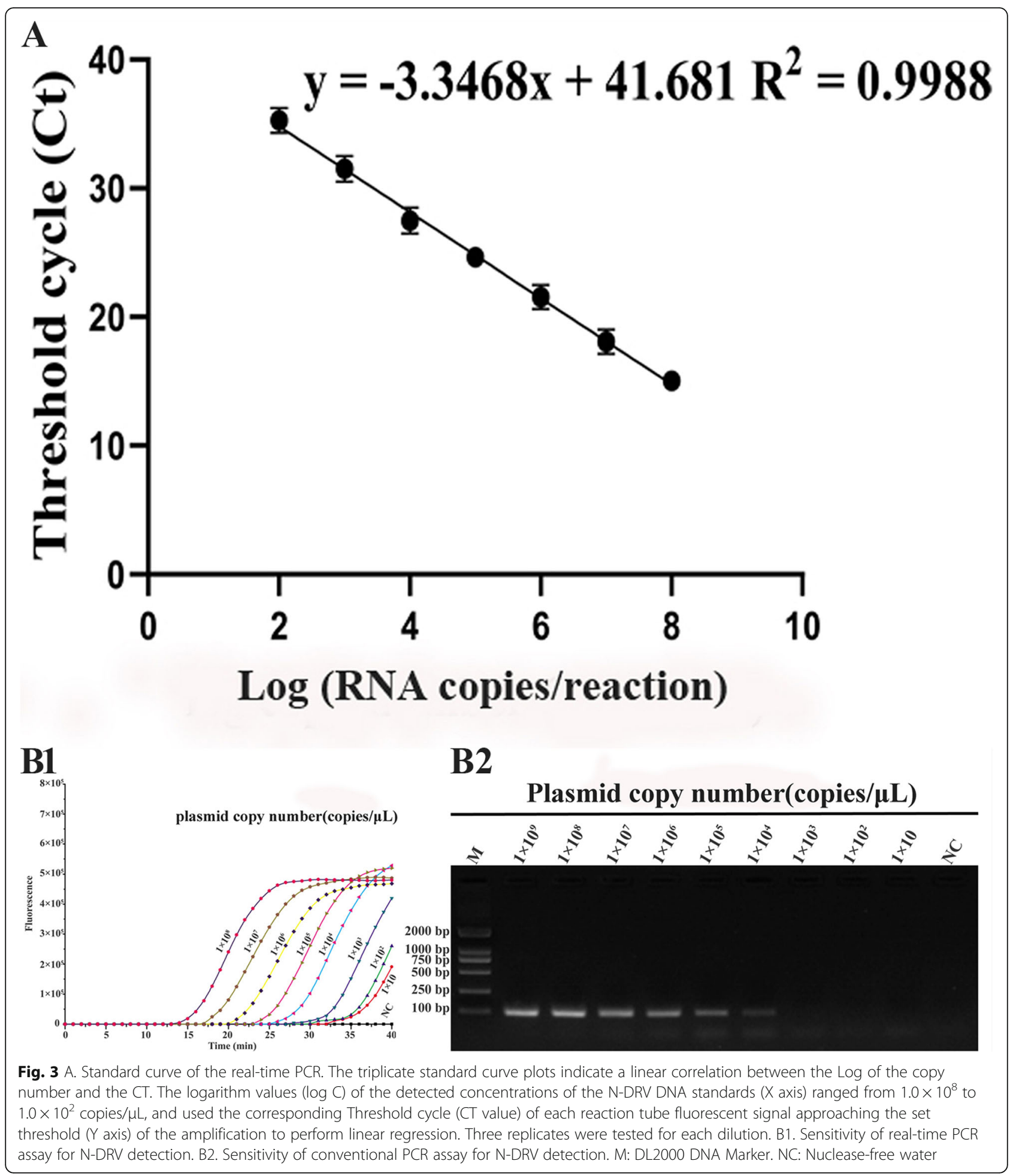

hemorrhage and necrosis in the liver. There are several notable different properties between classical MDRV and NDRV, including different antigenicity by cross-neutralization tests, host species differences, pathogenic properties, protein profiles [27-29], electropherotypes, and genomic coding assignments $[10-13,16,30]$. As fatal pathogenic viruses that can kill ducklings within $72 \mathrm{~h}$, NDRV had caused huge economic losses for the duck industry over the past several decades [31]. Therefore, an easy rapid highly 
Table 2 Intra- and inter- assay variability of Ct values of assay in detection of NDRV

\begin{tabular}{|c|c|c|c|c|c|c|c|c|}
\hline \multirow{3}{*}{$\begin{array}{l}\text { Copies } \\
\text { of } \\
\text { standard } \\
\text { plasmid } \\
\text { DNA }\end{array}$} & \multicolumn{4}{|c|}{ Intra-assay variability of Ct values } & \multicolumn{4}{|c|}{ Interassay variability of $\mathrm{Ct}$ values } \\
\hline & \multirow{2}{*}{$\begin{array}{l}\text { Proportion } \\
\text { of positive } \\
\text { Samples }^{a}\end{array}$} & \multicolumn{3}{|l|}{$\mathrm{Ct}$} & \multirow{2}{*}{$\begin{array}{l}\text { Proportion } \\
\text { of positive } \\
\text { Samples }\end{array}$} & \multicolumn{3}{|l|}{$\mathrm{Ct}$} \\
\hline & & Mean & SD & CV (\%) & & Mean & SD & CV $(\%$, \\
\hline $10^{8}$ & 1.00 & 15.04 & 0.03 & 0.20 & 1.00 & 15.20 & 0.20 & 1.32 \\
\hline $10^{7}$ & 1.00 & 17.47 & 0.06 & 0.34 & 1.00 & 17.69 & 0.17 & 0.96 \\
\hline $10^{6}$ & 1.00 & 20.72 & 0.23 & 1.11 & 1.00 & 20.50 & 0.10 & 0.49 \\
\hline $10^{5}$ & 1.00 & 23.94 & 0.13 & 0.54 & 1.00 & 23.78 & 0.28 & 1.18 \\
\hline $10^{4}$ & 1.00 & 27.11 & 0.02 & 0.07 & 1.00 & 27.85 & 0.78 & 2.80 \\
\hline $10^{3}$ & 1.00 & 30.79 & 0.45 & 1.46 & 1.00 & 30.91 & 0.90 & 2.91 \\
\hline $10^{2}$ & 1.00 & 34.32 & 0.13 & 0.38 & 1.00 & 34.15 & 0.54 & 1.58 \\
\hline 10 & 1.00 & 37.84 & 0.56 & 1.48 & 1.00 & 37.24 & 0.35 & 0.94 \\
\hline
\end{tabular}

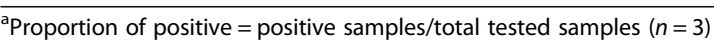

sensitive and specific method for NDRV detection is crucially required to develop [23].

In this study, we designed the probe and primers used in the study based on the S2 gene of NDRV. By using the mVISTA online program, we found that primers (NDRV-F and NDRV-R) and probe (NDRV-P) distinguished duck reovirus from other reoviruses. Then, a TaqMan-based real-time PCR for detecting NDRV infection was established. Verified by a series of experiments, the RT-qPCR has high sensitivity, specificity, and reproducibility. The sensitivity of the RT-qPCR was evaluated using ten-fold diluted DNA standard plasmid, and the lowest amount of detection for NDRV was found was $1.0 \times 10^{1}$ copies $/ \mu \mathrm{L}$ (Ct values: 38.3 ). It's thousands of times higher than conventional PCR $\left(1.0 \times 10^{4}\right.$ copies/ $\mu \mathrm{L})$. In subsequent experiments, the RT-qPCR showed high analytical specificity because other duck-derived pathogens were not detected, including Avian influenza virus (H9N2 AIV), Duck Tembusu virus (DTMUV), Goose parvovirus (GPV), Novel goose parvovirus (NGPV), Duck hepatitis virus type 1 and 3 (DHAV-1 and DHAV-3), Duck circovirus (DuCV), Duck Plague Virus (DPV). The RT-qPCR assay was also found to be highly reproducible. The variability of intra-assay and interassay were $\leq 1.48$ and $2.91 \%$, respectively.

The performance of the RT-qPCR assay used as a diagnostic tool to rapidly detect the NDRV is confirmed by the tested results using one hundred and twenty clinical specimens from suspected cases of infected ducks from different regions of China. These clinical samples, spleen samples, were obtained from different duck farms and laboratory diagnostic cases. Comparative analysis of the conventional PCR and RT-qPCR assay using clinical samples showed significant differences. The positive rate

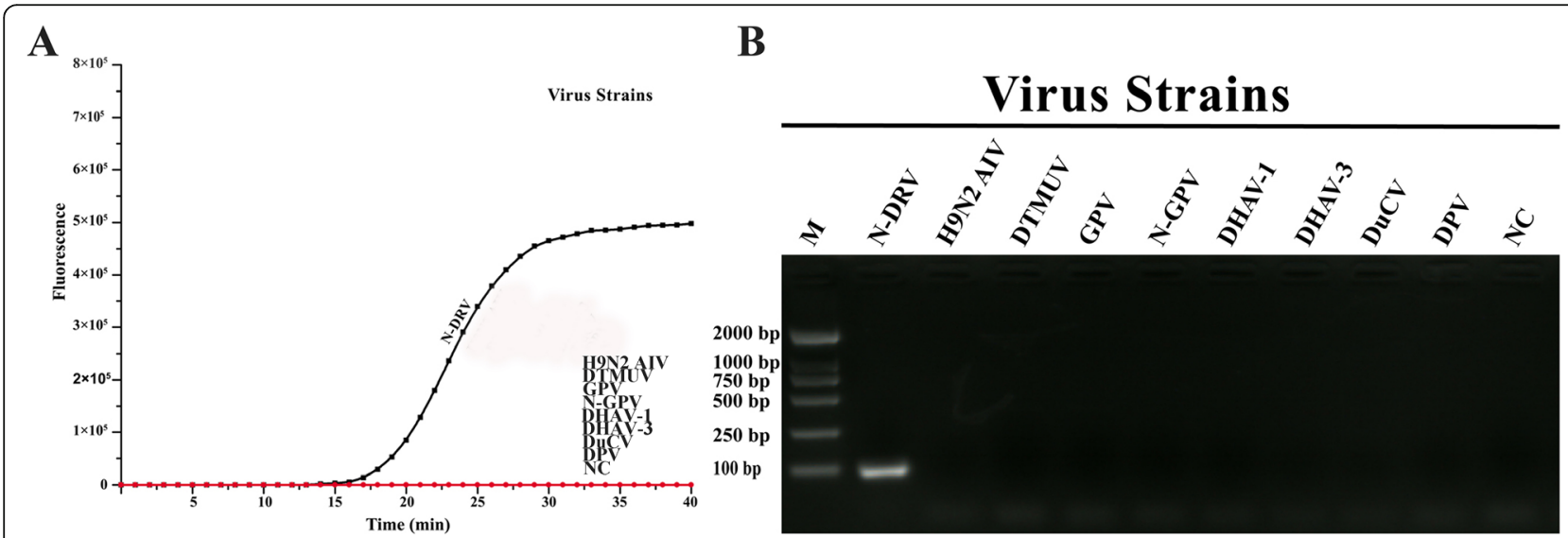

Fig. 4 Specificity test results of real-time PCR assay using different virus strains. a Amplification plots of different virus strains. $\mathbf{b}$ Results of Agarose gel electrophoresis. N-DRV: New duck reovirus. H9N2 AIV: Avian influenza virus. DTMUV: Duck tembusu virus. GPV: Goose parvovirus. N-GPV: Novel goose parvovirus. DHAV-1: Duck hepatitis virus type 1. DHAV-3: Duck hepatitis virus type 3. DuCV: Duck circovirus. DPV: Duck Plague Virus. M: DL2000 DNA Marker. NC: Nuclease-free water 


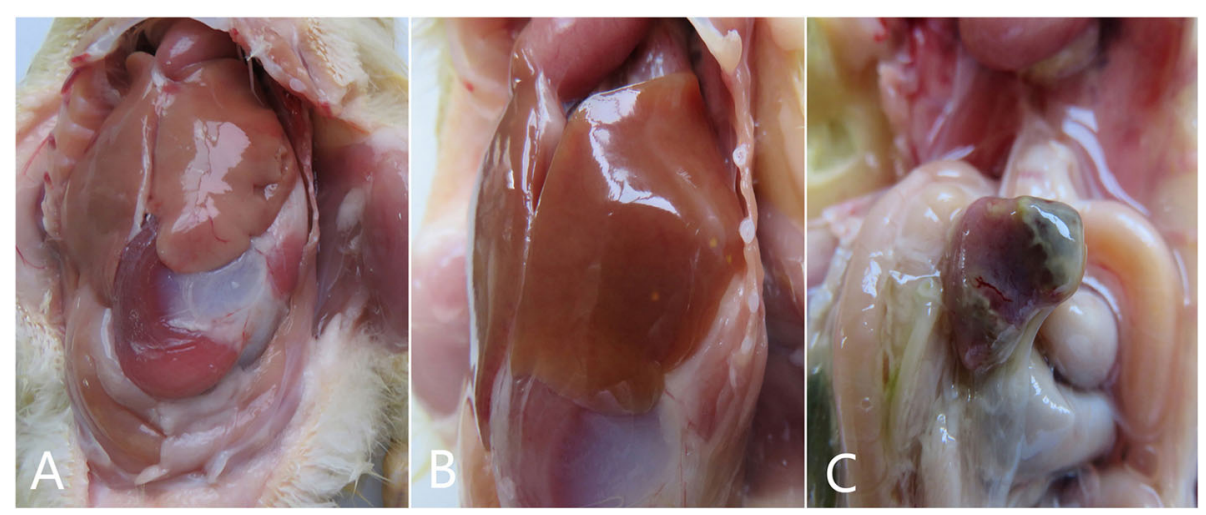

Fig. 5 Pathological changes of N-DRV afected 1-day-old ducklings. a Control group. b Hepatomegaly, bleeding, brittle texture and hemorrhagic necrosis. c Splenomegaly, patchy hemorrhagic necrosis

of infection of conventional PCR was merely $84.17 \%$ while RT-qPCR was $94.17 \%$. This has demonstrated the higher sensitivity of the TaqMan-based real-time PCR.

\section{Conclusions}

The RT-qPCR could be used as a reliable tool for the rapid detection of NDRV clinical samples, thereby facilitating epidemiological investigations of animals infected with NDRV.

\section{Methods}

\section{Virus isolation}

In this study, we isolated the reovirus from Cherry Valley duck [18] in Shandong province, China. The DRV field strain were isolated from spleen tissues of sick bird which showed symptoms of NDRV infections. The necrotic spleen tissue was extracted from sick birds, homogenized in phosphate-buffered saline (PBS, pH 7.2), freeze-thawed three times, and centrifuged at $8000 \times \mathrm{g}$ for 15 min $[18,32]$. The virus was isolated in LMH (Leghorn Male-chicken Hepatocellular-carcinoma, ATCC CRL2013) cell and named SDHZYC. The cultures were incubated at $37^{\circ} \mathrm{C}$ with $5 \% \mathrm{CO}_{2}$ and checked daily for giant or bloom-like cytopathic effects (CPEs). The virus was collected when we observed more than $80 \%$ CPEs. Then, we subculture virus until a stable CPE could be harvested and stored at $-80^{\circ} \mathrm{C}[18,32]$. The institute of avian disease in Shandong Agricultural University propagated other avian viruses (Avian influenza virus (H9N2 AIV), Duck Tembusu virus, Goose parvovirus, Novel goose parvovirus, Duck hepatitis virus type 1 and 3, Duck circovirus, Duck Plague Virus) in of 9- to 11-dayold embryonated specific-pathogen-free (SPF) eggs (Poultry research institute, Shandong Academy of Agricultural Sciences, Jinan, China) through chorioallantoic membrane route or chorioallantoic sac route [32].

\section{Experimental infection of ducklings}

Eighteen 1-day-old cherry valley ducklings have divided ducklings into 2 groups (9 ducklings in each group) randomly. To study the NDRV infection, group 1 was intramuscularly injected with $0.2 \mathrm{~mL}\left(10^{6.367} \mathrm{ELD}_{50}\right)$ of the NDRV cell fluid. As the control group, group 2 was treated with sterile DMEM $(500 \mathrm{~mL}$, Catalog 01-1721ACS; BI, Shanghai, China) in the same way. All ducklings were purchased from the commercial hatchery of Yike Company Limited in Xintai County. All experiments with ducks were fed and managed at Shandong Agricultural University according to the established humane procedures and biosecurity guidelines. Water and food were fed ad libitum and were provided living conditions of $40-60 \%$ relative humidity and a $12 / 12 \mathrm{~h}$ light/ dark cycle every day. All ducklings were observed and euthanatized using intravenous pentobarbital sodium (New Asia Pharmaceutical, Hainan, China) for $72 \mathrm{~h}$ post-infection (hpi) [23].

\section{RNA and DNA extraction}

Total RNAs (RNA viruses, i.e. H9N2 AIV, DTMUV, DHAV-1 and DHAV-3, NDRV) were extracted by MiniBEST Universal RNA Extraction Kit (50 preps, Catalog DP430; TIANGEN, Beijing, China) following the manufacturer's instructions. Total DNAs (DNA viruses, i.e. GPV, N-GPV, DuCV, and DPV) were extracted using TIANamp Genomic DNA Kit $(50$ preps, Catalog DP304-02; TIANGEN, Beijing, China) according to instructions provided by the manufacturer [33]. All extracted RNAs and DNAs templates were stored at $80^{\circ} \mathrm{C}$ until use.

\section{Sequence analysis}

According to reports [31], the sigma $\mathrm{C}$ is the major antigenic determinant of avian reovirus. Structural protein Sigma $\mathrm{C}$ was the main protein of avian 
Table 3 Conventional RT-PCR assay and real-time PCR assay detect thirty-nine samples respectively from different affected organs at 24, 48 and $72 \mathrm{~h}$

\begin{tabular}{|c|c|c|c|c|c|c|c|c|}
\hline \multirow{3}{*}{$\frac{\text { No }}{1}$} & \multirow{3}{*}{$\begin{array}{l}\text { Samples } \\
\text { Heart (24hpi) }\end{array}$} & \multicolumn{2}{|c|}{ Conventional RT-PCR assay } & \multicolumn{5}{|l|}{ Real-time PCR assay } \\
\hline & & \multirow{2}{*}{$\begin{array}{l}\text { Number of positive/ } \\
\text { Number of samples } \\
0 / 3\end{array}$} & \multirow{2}{*}{$\begin{array}{l}\text { Positive rate(\%) } \\
0\end{array}$} & \multirow{2}{*}{$\begin{array}{l}\text { Number of positive/ } \\
\text { Number of samples } \\
0 / 3\end{array}$} & \multirow{2}{*}{$\begin{array}{l}\text { Positive } \\
\text { rate(\%) }\end{array}$} & \multicolumn{3}{|c|}{ viral copy numbers } \\
\hline & & & & & & Neg. & Neg. & Neg. \\
\hline 2 & Liver (24hpi) & $0 / 3$ & 0 & $0 / 3$ & 0 & Neg. & Neg. & Neg. \\
\hline 3 & Spleen (24hpi) & $2 / 3$ & 66.7 & $2 / 3$ & 66.7 & $10^{2.8}$ & Neg. & $10^{1.7}$ \\
\hline 4 & Lung (24hpi) & $3 / 3$ & 100 & $3 / 3$ & 100 & $10^{3.4}$ & $10^{4.2}$ & $10^{4.9}$ \\
\hline 5 & Kidney(24hpi) & $0 / 3$ & 0 & $0 / 3$ & 0 & Neg. & Neg. & Neg. \\
\hline 6 & Pancreas(24hpi) & $0 / 3$ & 0 & $0 / 3$ & 0 & Neg. & Neg. & Neg. \\
\hline 7 & Stomach(24hpi) & $0 / 3$ & 0 & $1 / 3$ & 33.3 & Neg. & Neg. & $10^{0.9}$ \\
\hline 8 & Brain (24hpi) & $3 / 3$ & 100 & $3 / 3$ & 100 & $10^{2.7}$ & $10^{3.4}$ & $10^{2.0}$ \\
\hline 9 & Intestinal(24hpi) & $0 / 3$ & 0 & $0 / 3$ & 0 & Neg. & Neg. & Neg. \\
\hline 10 & Bursa(24hpi) & $1 / 3$ & 33.3 & $2 / 3$ & 66.7 & Neg. & $10^{2.9}$ & $10^{2.4}$ \\
\hline 11 & Thymus (24hpi) & $0 / 3$ & 0 & $2 / 3$ & 66.7 & $10^{3.4}$ & $10^{2.5}$ & Neg. \\
\hline 12 & Stool(24hpi) & $0 / 3$ & 0 & $0 / 3$ & 0 & Neg. & Neg. & Neg. \\
\hline 13 & Serum (24hpi) & $2 / 3$ & 66.7 & $2 / 3$ & 66.7 & $10^{2.8}$ & $10^{3.9}$ & Neg. \\
\hline 14 & Heart (48hpi) & $2 / 3$ & 66.7 & $3 / 3$ & 100 & $10^{1.3}$ & $10^{2.4}$ & $10^{2.6}$ \\
\hline 15 & Liver (48hpi) & $1 / 3$ & 33.3 & $2 / 3$ & 66.7 & $10^{2.9}$ & $10^{2.1}$ & Neg. \\
\hline 16 & Spleen (48hpi) & $3 / 3$ & 100 & $3 / 3$ & 100 & $10^{4.2}$ & $10^{3.3}$ & $10^{2.5}$ \\
\hline 17 & Lung (48hpi) & $3 / 3$ & 100 & $3 / 3$ & 100 & $10^{3.7}$ & $10^{2.1}$ & $10^{3.0}$ \\
\hline 18 & Kidney(48hpi) & $1 / 3$ & 33.3 & $2 / 3$ & 66.7 & $10^{2.6}$ & $10^{2.5}$ & Neg. \\
\hline 19 & Pancreas(48hpi) & $2 / 3$ & 66.7 & $2 / 3$ & 66.7 & $10^{2.2}$ & $10^{2.8}$ & Neg. \\
\hline 20 & Stomach(48hpi) & $3 / 3$ & 100 & $3 / 3$ & 100 & $10^{2.3}$ & $10^{2.3}$ & $10^{2.5}$ \\
\hline 21 & Brain (48hpi) & $3 / 3$ & 100 & $3 / 3$ & 100 & $10^{2.2}$ & $10^{3.2}$ & $10^{3.1}$ \\
\hline 22 & Intestinal(48hpi) & $1 / 3$ & 33.3 & $2 / 3$ & 66.7 & $10^{5.8}$ & Neg. & $10^{5.8}$ \\
\hline 23 & Bursa(48hpi) & $3 / 3$ & 100 & $3 / 3$ & 100 & $10^{2.3}$ & $10^{3.9}$ & $10^{2.8}$ \\
\hline 24 & Thymus (48hpi) & $1 / 3$ & 33.3 & $2 / 3$ & 66.7 & Neg. & $10^{2.6}$ & $10^{3.0}$ \\
\hline 25 & Stool(48hpi) & $3 / 3$ & 100 & $3 / 3$ & 100 & $10^{4.7}$ & $10^{4.5}$ & $10^{4.8}$ \\
\hline 26 & Serum (48hpi) & $3 / 3$ & 100 & $3 / 3$ & 100 & $10^{3.5}$ & $10^{3.5}$ & $10^{3.4}$ \\
\hline 27 & Heart (72hpi) & $2 / 3$ & 66.7 & $3 / 3$ & 100 & $10^{2.6}$ & $10^{2.8}$ & $10^{2.9}$ \\
\hline 28 & Liver (72hpi) & $3 / 3$ & 100 & $3 / 3$ & 100 & $10^{2.6}$ & $10^{2.5}$ & $10^{1.8}$ \\
\hline 29 & Spleen (72hpi) & $3 / 3$ & 100 & $3 / 3$ & 100 & $10^{5.4}$ & $10^{7.4}$ & $10^{5.2}$ \\
\hline 30 & Lung (72hpi) & $3 / 3$ & 100 & $3 / 3$ & 100 & $10^{4.9}$ & $10^{5.6}$ & $10^{4.2}$ \\
\hline 31 & Kidney(72hpi) & $3 / 3$ & 100 & $3 / 3$ & 100 & $10^{2.0}$ & $10^{3.8}$ & $10^{3.2}$ \\
\hline 32 & Pancreas(72hpi) & $3 / 3$ & 100 & $3 / 3$ & 100 & $10^{2.4}$ & $10^{1.9}$ & $10^{3.2}$ \\
\hline 33 & Stomach(72hpi) & $3 / 3$ & 100 & $3 / 3$ & 100 & $10^{2.5}$ & $10^{3.5}$ & $10^{3.1}$ \\
\hline 34 & Brain (72hpi) & $3 / 3$ & 100 & $3 / 3$ & 100 & $10^{2.4}$ & $10^{4.6}$ & $10^{3.1}$ \\
\hline 35 & Intestinal(72hpi) & $3 / 3$ & 100 & $3 / 3$ & 100 & $10^{5.4}$ & $10^{6.8}$ & $10^{6.2}$ \\
\hline 36 & Bursa(72hpi) & $3 / 3$ & 100 & $3 / 3$ & 100 & $10^{5.3}$ & $10^{6.0}$ & $10^{6.3}$ \\
\hline 37 & Thymus (72hpi) & $3 / 3$ & 100 & $3 / 3$ & 100 & $10^{2.9}$ & $10^{2.9}$ & $10^{2.6}$ \\
\hline 38 & Stool(72hpi) & $3 / 3$ & 100 & $3 / 3$ & 100 & $10^{6.5}$ & $10^{6.2}$ & $10^{4.7}$ \\
\hline 39 & Serum (72hpi) & $3 / 3$ & 100 & $3 / 3$ & 100 & $10^{3.9}$ & $10^{3.9}$ & $10^{4.0}$ \\
\hline
\end{tabular}


Table 4 List of RT-qPCR and conventional RT-PCR results for clinical samples for NDRV

\begin{tabular}{lll}
\hline Result by & CPCR & $\begin{array}{l}\text { No. of samples } \\
\text { (total, 120) }\end{array}$ \\
\hline RT-qPCR & Pos. & 101 \\
\hline Pos. $^{\text {b }}$ & Neg. & 7 \\
Neg. ${ }^{c}$ & Neg. & 12 \\
Pos. & Pos. & 0 \\
Neg. &
\end{tabular}

${ }^{a} \mathrm{CPCR}$, conventional RT-PCR

${ }^{\mathrm{b}}$ Pos., Positive

'Neg., Negative

reovirus. It is in the shell of the virus, carried the surface antigen of virus type-specific neutralization reaction. It is related to the adsorption, proliferation, and syncytial formation of the virus. Therefore, it is of great significance to analyze the genetic evolution of Sigma C protein. The S1 segment encoding sigma $C$ gene of NDRV was amplified by primers $\sigma \mathrm{C}$ fulllength (Forward primer) and $\sigma \mathrm{C}$ full-length (Reverse primer) (Table 1). Amplified PCR products were separated on a $1 \%$ agarose gel and then purified using the Agarose Gel DNA Purification Kit (200 preps, Catalog D2500-02; OMEGA, Georgia, USA). The PCR products were cloned into the pMD18-T vector (20 preps, Catalog 6011; Takara, Beijing, China) and transformed the positive recombinant plasmid into DH $5 \alpha$ competent cells $(10 \times 100 \mu \mathrm{L}$, Catalog BC102-01; Biomed, Beijing, China). Then, the samples were sent to the Beijing Genomics Institute to be sequenced. The sequencing sequences were assembled into a complete $966 \mathrm{bp}$ sequence using the SeqMan program of the DNAstar software package (version 7.1) (DNAstar, Madison, WI, USA). Afterward, the sequence was aligned with other reovirus sequences using the MegAlign program of the DNA star package [34]. Utilizing the neighbor-joining method, a phylogenetic tree was constructed with MEGA 6.0 and performed 1000 bootstrap replicates. In Table 6, all the reference avian reovirus isolates were listed.

\section{RT-qPCR assay for NDRV}

Based on the obtained fluorescence and lowest threshold cycle $(\mathrm{Ct})$, the concentrations of the primers, probe, and templates were optimized [35]. The optimized RTqPCR of NDRV was reacted in a $20 \mu \mathrm{L}$ system (One Step PrimeScript ${ }^{\mathrm{tm}}$ RT-PCR Kit; Takara, Beijing, China). It contained $10 \mu \mathrm{L} 2 \times$ One-Step RT-PCR Buffer III, $0.4 \mu \mathrm{L}$ TaKaRa Ex Taq HS (5 U/ $\mu \mathrm{L}), 0.4 \mu \mathrm{L}$ PrimeScript RT Enzyme Mix II (200 units/ $\mu \mathrm{L}$ ), $0.4 \mu \mathrm{L}$ Realtime PCR forward primer $(10 \mu \mathrm{M}), 0.4 \mu \mathrm{L}$ Realtime PCR reserve primer $(10 \mu \mathrm{M}), 0.8 \mu \mathrm{L}$ Realtime PCR probe $(10 \mu \mathrm{M})$, $0.4 \mu \mathrm{L}$ ROX Reference Dye $(50 \times), 5.6 \mu \mathrm{L} \mathrm{ddH}_{2} \mathrm{O}$, and
2.0 $\mu \mathrm{L}$ RNA template. The RT-qPCR was conducted with Applied Biosystems 7300 FAST Real-Time PCR System. The reaction conditions include $42{ }^{\circ} \mathrm{C}$ for $5 \mathrm{~min}$ and $95^{\circ} \mathrm{C}$ for $10 \mathrm{~s}, 40$ cycles at $95^{\circ} \mathrm{C}$ for $5 \mathrm{~s}$, and $60^{\circ} \mathrm{C}$ for $20 \mathrm{~s}$. During the extension step, Fluorescent signals were collected. We analyzed the result of each assay with Sequence Detector software (version 2.1; Applied Biosystems).

\section{Standard plasmid preparation, construct standard curves and sensitivity}

The forward primer (RT-qPCR-F) and reverse primer (RT-qPCR-R) were used to amplify the partial S2 gene ( $85 \mathrm{bp}$ ) of NDRV. The PCR products were separated by electrophoresis on $1.0 \%$ agarose gel. The PCR product was cloned into pMD18-T (the plasmid vector) and then was verified by sequencing [36]. The plasmid of pMD18-NDRV was serially diluted from $1.0 \times 10^{10}$ copies $/ \mu \mathrm{L}$ to $1.0 \times 10^{1}$ copies $/ \mu \mathrm{L}$ by $10 \times$ Tris-EDTA Buffer ( $\mathrm{pH} 7.4$ ), and stored at $-20^{\circ} \mathrm{C}$. The $10 \times$ Tris-EDTA Buffer ( $\mathrm{pH} 7.4)$ is prepared by TrisEDTA Buffer $10 \times$ Powder, pH 7.4 (10 pouches, Cata$\log$ T9111; Takara, Beijing, China) dissolved in water. Then, it was used to construct the standard curve [19] and confirm the detection limit of RT-qPCR.

\section{Conventional PCR for NDRV}

Meanwhile, conventional PCR (cPCR) was conducted [37] under the same circumstances. The primers used for the $\mathrm{CPCR}$ were showed in Table 1 . The reaction conditions include $95^{\circ} \mathrm{C}$ for $5 \mathrm{~min}, 35$ cycles at $95^{\circ} \mathrm{C}$ for $30 \mathrm{~s}, 55^{\circ} \mathrm{C}$ for $30 \mathrm{~s}$ and $72{ }^{\circ} \mathrm{C}$ for $30 \mathrm{~s}$; and $72^{\circ} \mathrm{C}$ for $5 \mathrm{~min}$ at last. The sensitivity of the $\mathrm{cPCR}$ was confirmed by agarose gel electrophoresis. Nucleasefree water was used as the negative control in RTqPCR determination. And all reactions were repeated three times.

\section{Specificity analysis of the RT-qPCR reaction}

Other duck-derived viruses were used to prove the specificity of the RT-qPCR reaction, including Avian influenza virus (H9N2 AIV), Duck tembusu virus (DTMUV), Goose parvovirus (GPV), Novel goose parvovirus (N-GPV), Duck hepatitis virus type 1 and 3 (DHAV-1 and DHAV-3), Duck circovirus (DuCV), Duck Plague Virus (DPV). The RT-qPCR assay was performed in triplicate.

\section{Repeatability analysis of the RT-qPCR assay}

To evaluate the coefficient of variation (CV) of the RTqPCR, the 10-fold dilutions of pMD18-S2 (concentration of $1.0 \times 10^{8}$ to $1.0 \times 10^{1}$ copies $/ \mu \mathrm{L}$ ) were tested. In checking to see the intra-batch repeatability, triplicates of each dilution were detected, and according to the 
Table 5 Copy number of clinical samples

\begin{tabular}{|c|c|c|c|c|c|c|c|c|}
\hline No & Sample source & CT value & No & Sample source & CT value & No & Sample source & CT value \\
\hline 1 & Weifang (Shandong) & 16.1241 & 41 & Weifang (Shandong) & 13.695 & 81 & Linyi (Shandong) & 15.1162 \\
\hline 2 & Weifang (Shandong) & 13.1678 & 42 & Weifang (Shandong) & 21.1731 & 82 & Dangshan (Anhui) & 13.9539 \\
\hline 3 & Weifang (Shandong) & 25.1597 & 43 & Weifang (Shandong) & 24.7179 & 83 & Dangshan (Anhui) & 24.9559 \\
\hline 4 & Weifang (Shandong) & 26.5132 & 44 & Weifang (Shandong) & 13.0328 & 84 & Dangshan (Anhui) & 13.846 \\
\hline 5 & Weifang (Shandong) & 19.0494 & 45 & Weifang (Shandong) & Neg. & 85 & Dangshan (Anhui) & 21.5004 \\
\hline 6 & Weifang (Shandong) & 21.8586 & 46 & Weifang (Shandong) & 24.1907 & 86 & Dangshan (Anhui) & 15.1966 \\
\hline 7 & Weifang (Shandong) & 25.3857 & 47 & Weifang (Shandong) & 20.7851 & 87 & Dangshan (Anhui) & Neg. \\
\hline 8 & Weifang (Shandong) & 22.4812 & 48 & Weifang (Shandong) & 23.6762 & 88 & Dangshan (Anhui) & 21.2269 \\
\hline 9 & Weifang (Shandong) & 13.1635 & 49 & Weifang (Shandong) & 13.159 & 89 & Dangshan (Anhui) & 13.1864 \\
\hline 10 & Weifang (Shandong) & 16.8451 & 50 & Weifang (Shandong) & 20.3433 & 90 & Dangshan (Anhui) & 18.0723 \\
\hline 11 & Weifang (Shandong) & 21.8283 & 51 & Weifang (Shandong) & Neg. & 91 & Dangshan (Anhui) & 23.813 \\
\hline 12 & Weifang (Shandong) & 22.472 & 52 & Weifang (Shandong) & 20.1206 & 92 & Dangshan (Anhui) & Neg. \\
\hline 13 & Weifang (Shandong) & 20.3765 & 53 & Weifang (Shandong) & 20.0127 & 93 & Dangshan (Anhui) & 24.0662 \\
\hline 14 & Weifang (Shandong) & 25.9252 & 54 & Weifang (Shandong) & 13.0581 & 94 & Dangshan (Anhui) & 14.9209 \\
\hline 15 & Weifang (Shandong) & 17.833 & 55 & Weifang (Shandong) & 17.0726 & 95 & Dangshan (Anhui) & 13.9889 \\
\hline 16 & Weifang (Shandong) & 20.8678 & 56 & Linyi (Shandong) & 14.9147 & 96 & Dangshan (Anhui) & 24.7853 \\
\hline 17 & Weifang (Shandong) & 23.8947 & 57 & Linyi (Shandong) & 21.283 & 97 & Dangshan (Anhui) & 21.1174 \\
\hline 18 & Weifang (Shandong) & 16.022 & 58 & Linyi (Shandong) & 23.7864 & 98 & Dangshan (Anhui) & 19.674 \\
\hline 19 & Weifang (Shandong) & 21.404 & 59 & Linyi (Shandong) & 20.1406 & 99 & Dangshan (Anhui) & 21.1937 \\
\hline 20 & Weifang (Shandong) & 23.0637 & 60 & Linyi (Shandong) & 13.6614 & 100 & Dangshan (Anhui) & 17.0916 \\
\hline 21 & Weifang (Shandong) & 14.28 & 61 & Linyi (Shandong) & 26.6927 & 101 & Dangshan (Anhui) & 15.1441 \\
\hline 22 & Weifang (Shandong) & 14.2534 & 62 & Linyi (Shandong) & 17.2705 & 102 & Dangshan (Anhui) & 24.7838 \\
\hline 23 & Weifang (Shandong) & 13.925 & 63 & Linyi (Shandong) & 19.4452 & 103 & Xuzhou (Jiangsu) & 20.488 \\
\hline 24 & Weifang (Shandong) & 13.964 & 64 & Linyi (Shandong) & 13.7376 & 104 & Xuzhou (Jiangsu) & 17.6883 \\
\hline 25 & Weifang (Shandong) & 24.5377 & 65 & Linyi (Shandong) & 26.75 & 105 & Xuzhou (Jiangsu) & 24.3292 \\
\hline 26 & Weifang (Shandong) & 24.459 & 66 & Linyi (Shandong) & 17.3734 & 106 & Xuzhou (Jiangsu) & 15.0757 \\
\hline 27 & Weifang (Shandong) & 24.7221 & 67 & Linyi (Shandong) & 13.8337 & 107 & Xuzhou (Jiangsu) & 14.9268 \\
\hline 28 & Weifang (Shandong) & 21.422 & 68 & Linyi (Shandong) & 17.367 & 108 & Xuzhou (Jiangsu) & 13.7254 \\
\hline 29 & Weifang (Shandong) & 21.525 & 69 & Linyi (Shandong) & 13.0877 & 109 & Xuzhou (Jiangsu) & 17.5209 \\
\hline 30 & Weifang (Shandong) & 21.4153 & 70 & Linyi (Shandong) & 23.5349 & 110 & Xuzhou (Jiangsu) & 18.5054 \\
\hline 31 & Weifang (Shandong) & 18.3021 & 71 & Linyi (Shandong) & 14.8449 & 111 & Xuzhou (Jiangsu) & 15.009 \\
\hline 32 & Weifang (Shandong) & 18.3309 & 72 & Linyi (Shandong) & 16.8813 & 112 & Xuzhou (Jiangsu) & 21.9341 \\
\hline 33 & Weifang (Shandong) & 18.3773 & 73 & Linyi (Shandong) & 13.0384 & 113 & Xuzhou (Jiangsu) & 16.7821 \\
\hline 34 & Weifang (Shandong) & 15.6995 & 74 & Linyi (Shandong) & 24.0116 & 114 & Xuzhou (Jiangsu) & 18.1889 \\
\hline 35 & Weifang (Shandong) & Neg. & 75 & Linyi (Shandong) & 14.8421 & 115 & Xuzhou (Jiangsu) & 17.4116 \\
\hline 36 & Weifang (Shandong) & 15.7435 & 76 & Linyi (Shandong) & 17.9888 & 116 & Xuzhou (Jiangsu) & Neg. \\
\hline 37 & Weifang (Shandong) & 15.7018 & 77 & Linyi (Shandong) & 19.8084 & 117 & Xuzhou (Jiangsu) & 17.7065 \\
\hline 38 & Weifang (Shandong) & 13.6976 & 78 & Linyi (Shandong) & 15.133 & 118 & Xuzhou (Jiangsu) & 13.7366 \\
\hline
\end{tabular}

formula of the geometric mean Cq values / standard deviation calculated the coefficients of variation $(\mathrm{CV})$. The coefficient of variation for inter-assay repeatability shows the differences among the measures at different times [33]. Three repeats were performed for each of the inter and intra assay analysis.

\section{Clinical samples detection}

During 2017-2018, we collected 120 samples of spleen from suspected cases of infected ducks. According to the survey, these samples were collected from different regions of Weifang (Shandong), Linyi (Shandong), Dangshan (Anhui), and Xuzhou (Jiangsu). One hundred 
Table 6 Description of the Avian reovirus isolates involved in this study

\begin{tabular}{|c|c|c|c|}
\hline Isolates & Accession number & Host & Country \\
\hline TU399 & HM751135 & Avian & Tunis \\
\hline TU430 & HM751137 & Avian & Tunis \\
\hline TU96 & HM751139 & Avian & Tunis \\
\hline TU97.2 & HM751141 & Avian & Tunis \\
\hline TU420 & HM751143 & Avian & Tunis \\
\hline TU5 & HM751145 & Avian & Tunis \\
\hline TU105B6 & HM751147 & Avian & Tunis \\
\hline TU1390 & HM751149 & Avian & Tunis \\
\hline S1133 & AF330703 & Avian & Spain \\
\hline SD10-1 & KP288863 & Avian & China \\
\hline TARV-MN9 & KF872241 & Avian & USA \\
\hline TARV-MN10 & KF872242 & Avian & USA \\
\hline LY383 & MF183217 & Avian & China \\
\hline MW9710 & AY580159 & Muscovy duck & China \\
\hline ZJ99 & AY619690 & Muscovy duck & China \\
\hline C4 & DQ066924 & Muscovy duck & China \\
\hline S12 & DQ643970 & Muscovy duck & China \\
\hline TH11 & JX826587 & Duck & China \\
\hline NP03 & KC312699 & Duck & China \\
\hline QY & KF689545 & Duck & China \\
\hline S1 & KF154116 & Duck & China \\
\hline SDHZYC & MK789277 & Duck & China \\
\hline
\end{tabular}

and twenty clinical spleen samples were detected with the TaqMan based real-time PCR and conventional PCR assays (Primers and probe were presented in Table 1). The tissue samples from SPF duck embryo were used as controls.

\section{Statistical analysis}

Statistically significant differences in mean detection rates were determined by one-way ANOVA assessment using GraphPad Prism version 6 (GraphPad Software Inc., San Diego, Calif.) when different types of samples were tested. At ${ }^{*} P<0.05$, the difference was considered significant.

\section{Abbreviations}

ARV: Avian reovirus; CPCR: Conventional PCR; CPEs: Cytopathic effects; Ct: Threshold cycle; CV: Coefficient of variation; DHAV-1: Duck hepatitis virus I; DHAV-3: Duck hepatitis virus III; DPV: Duck plague virus; DRV: Duck reovirus; DTMUV: Duck tembusu virus; DuCV: Duck circovirus; GPV: Goose parvovirus; H9N2 AIV: H9 subtype avian influenza; LMH: Leghorn Male-chicken Hepatocellular-carcinoma; MDRV: Muscovy Duck Reovirus; NDRV: New duck reovirus; N-GPV: New goose parvovirus; RT-qPCR: TaqMan-based real-time PCR assay

\section{Acknowledgements}

Not applicable.

\section{Authors' contributions}

YT and YXD conceived, designed and guided the experiments, contributed substantially to the manuscript. SZ and WHL performed the experiment and statistical analysis and drafted the manuscript. XDL1 and XDL2 made a contribution to the experiment and revised the partial manuscript. BG made a contribution to the experiment including the isolation of the virus and so forth. All authors read and approved the final manuscript.

\section{Funding}

This work was fund by the National Key Research and Development Program of China (2018YFD0500106-3); The Shandong Mount Tai Industry Leadership Talent Project (LJNY201610). The funder provided funding support.

\section{Availability of data and materials}

All data generated or analyzed during this study are included in this article. The datasets (RNA sequencing data, GenBank accession number MK335954) generated and/or analysed during the current study are available in the $\mathrm{NCBI}$.

\section{Ethics approval and consent to participate}

The programs and procedures used in this study have been examined and approved by the Shandong Animal Ethics Commission (permit number: 2017360331). And follow all international, national, and institutional guidelines applicable to animal care and use. We obtained written informed consent to use the animals in our study from the owners of the animals.

\section{Consent for publication}

Not applicable.

\section{Competing interests}

Not applicable.

\section{Author details}

${ }^{1}$ College of Animal Science and Technology, Shandong Agricultural University, 61 Daizong Street, Tai'an 271018, Shandong Province, China.

${ }^{2}$ Shandong Provincial Key Laboratory of Animal Biotechnology and Disease Control and Prevention, Tai'an 271018, Shandong, China. ${ }^{3}$ Shandong Provincial Engineering Technology Research Center of Animal Disease Control and Prevention, Tai'an 271018, Shandong, China. ${ }^{4}$ College of Animal medical, Qingdao Agricultural University, Qingdao 266109, Shandong, China. ${ }^{5}$ Qingdao Yibang Bioengineering Co. Ltd., Qingdao 266000, Shandong, China

Received: 21 February 2020 Accepted: 14 August 2020

Published online: 25 August 2020

\section{References}

1. Malkinson MPKW. Reovirus infection of young muscovy ducks Cairina Moschata. Avian Pathol. 1981;10:433-40.

2. Kaschula VR. A new virus disease of the muscovy duck present in natal. Vet Med Assoc. 1950;21:18-26.

3. Gaudry TAC. Other reovirus infections. Dis Poultry. 1972;18:13-21.

4. AI PE. Evaluation of respiratory patterns of infants in the perioperative period. Anesthesiology. 1984;61:A420.

5. Hefels-Redmann UMHK. Structural and biological characteristics of reoviruses isolated from Muscovy ducks Cairina moschata. Avian Pathol. 1992:21:481-91.

6. Zhou F. Discovery of the pathogen of muscovy duck liver white spots disease. Fujian J Animal Husbandry Veterinary. 2000;6:1-3.

7. Gaudry D, Charles JM, Tektoff J. A new disease expressing itself by a viral pericarditis in Barbary ducks. Comptes rendus hebdomadaires des seances de I'Academie des sciences. Serie D: Sciences naturelles. 1972; 274:2916-9.

8. Yun $\mathrm{T}$, Chen $\mathrm{H}, \mathrm{Yu}$ B, Zhang $\mathrm{C}$, Chen $\mathrm{L}, \mathrm{Ni}$ Z, et al. Development and application of an indirect ELISA for the detection of antibodies to novel duck reovirus. J Virol Methods. 2015;220:55-9.

9. Liu Q, Zhang G, Huang Y, Ren G, Chen L, Gao J, et al. Isolation and characterization of a reovirus causing spleen necrosis in Pekin ducklings. Vet Microbiol. 2011;148:200-6. 
10. Wang D, Xu F, Ma G, Zhang C, Huang Y, Li H, et al. Complete genomic sequence of a new Muscovy duck-origin Reovirus from China. J Virol. 2012 86:1244-5.

11. Ma G, Wang D, Shi J, Jiang T, Yuan Y, Zhang D. Complete genomic sequence of a Reovirus isolate from Pekin ducklings in China. J Virol. 2012;86:1313-7.

12. Yun T, Ye W, Ni Z, Chen L, Yu B, Hua J, et al. Complete genomic sequence of goose-origin Reovirus from China. J Virol. 2012;86:1025-7.

13. Yun T, Yu B, Ni Z, Ye W, Chen L, Hua J, et al. Isolation and genomic characterization of a classical Muscovy duck reovirus isolated in Zhejiang, China. Infect Genet Evol. 2013;20:444-53.

14. Kuntz-Simon G, Le Gall-Recule G, de Boisseson C, Jestin V. Muscovy duck reovirus sigmaC protein is atypically encoded by the smallest genome segment. J General Virol. 2002:83:1189-200.

15. Chen S, Chen S, Lin F, Wang S, Jiang B, Cheng $X$, et al. The isolation and identification of novel duck reovirus. Chinese J Virol. 2012;28:224-30.

16. Yun T, Yu B, Ni Z, Ye W, Chen L, Hua J, et al. Genomic characteristics of a novel reovirus from Muscovy duckling in China. Vet Microbiol. 2014;168:261-71.

17. Farkas SL, Dandar E, Marton S, Feher E, Oldal M, Jakab F, et al. Detection of shared genes among Asian and European waterfowl reoviruses in the whole genome constellations. Infect Genet Evol. 2014;28:55-7.

18. Wang H, Gao B, Chen H, Diao XY, Tang Y. Isolation and characterization of a variant duck orthoreovirus causing spleen necrosis in Peking ducks, China. Transbound Emerg Dis. 2019;66:2033-44.

19. Niu X, Chen H, Yang J, Yu X, Ti J, Wang A, et al. Development of a TaqManbased real-time PCR assay for the detection of novel GPV. J Virol Methods. 2016:237:32-7.

20. Wang J, Wang J, Cui Y, Nan H, Yuan W. Development of a taqman-based real-time PCR assay for the rapid and specific detection of novel duckorigin goose parvovirus. Mol Cell Probes. 2017;34:56-8.

21. Niesters HG. Quantitation of viral load using real-time amplification techniques. Methods. 2001;25:419-29.

22. Mackay IM, Arden KE, Nitsche A. Real-time PCR in virology. Nucleic Acids Res. 2002;30:1292-305.

23. Li Z, Cai Y, Liang G, El-Ashram S, Mei M, Huang W, et al. Detection of novel duck reovirus (NDRV) using visual reverse transcription loop-mediated isothermal amplification (RT-LAMP). Sci Rep-Uk. 2018;8:14039.

24. Du X, Xiao R, Fu H, Yuan Z, Zhang W, Yin L, et al. Hypericin-loaded graphene oxide protects ducks against a novel duck reovirus. Mat Sci End C-Mater. 2019;105:110052.

25. Yun T, Hua J, Ye W, Yu B, Chen L, Ni Z, et al. Comparative proteomic analysis revealed complex responses to classical/novel duck reovirus infections in Cairna moschata. Sci Rep-Uk. 2018;8:10079.

26. Wu Q, Ding M, Li C, Liu G, Chen Z. Construction and characterization of an infectious molecular clone of novel duck reovirus. J Gen Virol. 2018;99:449-56.

27. Xiao R, Mi X, Sun J, Ding M, Li C, Zhu J, et al. Interaction between translocation-associated membrane protein 1 and sigma $C$ protein of novel duck reovirus controls virus infectivity. Virus Genes. 2020;56:347-53.

28. Hou X, Liu G, Zhang H, Hu X, Zhang X, Han F, et al. High-mobility group box 1 protein (HMGB1) from Cherry Valley duck mediates signaling pathways and antiviral activity. Vet Res. 2020;51:12

29. Du X, Ding M, Wu Q, Li C, Guo H, Liu G, et al. Characterization of a P18 protein in the $\mathrm{S} 1$ segment of the novel duck reovirus genome. Acta Virol. 2020;64:59-66

30. Chen Z, Zhu Y, Li C, Liu G. Outbreak-associated novel duck Reovirus, China, 2011. Emerg Infect Dis. 2012;18:1209-11.

31. Zheng $X$, Wang $D$, Ning $K$, Liang $T$, Wang $M$, Jiang $M$, et al. A duck reovirus variant with a unique deletion in the sigma $C$ gene exhibiting high pathogenicity in Pekin ducklings. Virus Res. 2016;215:37-41.

32. Chen H, Dou Y, Tang Y, Zhang Z, Zheng X, Niu X, et al. Isolation and genomic characterization of a duck-origin GPV-related parvovirus from Cherry Valley ducklings in China. PLoS One. 2015;10:e0140284.

33. Wan C, Chen C, Cheng L, Chen H, Fu Q, Shi S, et al. Specific detection of Muscovy duck parvovirus infection by TaqMan-based real-time PCR assay. BMC Vet Res. 2018;14:26-7

34. Wei Z, Liu H, Diao Y, Li X, Zhang S, Gao B, et al. Pathogenicity of fowl adenovirus (FAdV) serotype 4 strain SDJN in Taizhou geese. Avian Pathol. 2019:48:477-85.

35. Wan C, Chen C, Cheng L, Fu G, Shi S, Liu R, et al. Development of a TaqMan-based real-time PCR for detecting duck adenovirus 3. J Virol Methods. 2018;261:86-90.
36. Rong J, Cheng T, Liu X, Jiang T, Gu H, Zou G. Development of recombinant VP2 vaccine for the prevention of infectious bursal disease of chickens. Vaccine. 2005;23:4844-51.

37. Bin Gao. Isolation, Identification and Pathogenicity of a New Duck Reovirus: Shandong Agricultural University; 2019.

\section{Publisher's Note}

Springer Nature remains neutral with regard to jurisdictional claims in published maps and institutional affiliations.
Ready to submit your research? Choose BMC and benefit from:

- fast, convenient online submission

- thorough peer review by experienced researchers in your field

- rapid publication on acceptance

- support for research data, including large and complex data types

- gold Open Access which fosters wider collaboration and increased citations

- maximum visibility for your research: over $100 \mathrm{M}$ website views per year

At BMC, research is always in progress.

Learn more biomedcentral.com/submissions 